\title{
Isotopía en la imagen digital
}

\author{
Véronique Mondéjar
}

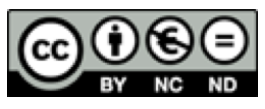

Esta obra está bajo una licencia Creative Commons

Reconocimiento-No comercial-Sin Obra Derivada 



\title{
Isotopía en la imagen digital
}

\author{
Véronique Mondéjar ${ }^{1}$ \\ Universidad Nacional de Colombia \\ vcmondejarm@unal.edu.co
}

Recibido: 17 de setiembre de 2015 Aprobado:18 de febrero de 2016

\section{Resumen}

La imagen digital conlleva un análisis procesual de orden hermenéutico a menudo inconsciente. En efecto, aunque la lectura de una fotografía es un acto instantáneo, se relega su apreciación a aspectos críticos que se apartan del panorama creativo desde el cual se emitió. Se distinguen, de este modo, aciertos plásticos en una escala de valores en estrecha relación con la oferta cultural del entorno propio a la exhibición de la obra. El acercamiento a una lectura semiótica posibilita la comprensión del universo connotativo inmerso en la imagen. Esta interpretación permite establecer acciones isotópicas que abren horizontes interactivos los cuales posibilitan una manipulación digital.

Palabras clave: imagen digital, fotografía, lectura, análisis, semiótica, isotopía, hermenéutica.

\begin{abstract}
The digital image often carries an unconscious analysis. Although the reading of photography is an instantaneous act, its appreciation is relegated to critical issues. The creative scene from which it was issued is always forgotten. The semiotic analysis allows the grasp of the plastics characteristics on a scale of values given the cultural and geopolitical background. A conscious reading provides an approach that enables a comprehensive understanding of the cultural background and its plastic values. This interpretation allows hermeneutic horizons that can interact with the isotopic work enabling digital manipulation.
\end{abstract}

Key words: digital image, photography, reading, analysis, semiotic, isotopy, hermeneutic.

\footnotetext{
${ }^{1}$ Nota de autor: Agradecimientos al programa de Doctorado en Ciencias Humanas y Sociales, Facultad de Ciencias Humanas y Económicas de la Universidad Nacional de Colombia, sede de Medellín.
} 


\section{Artículos}

La comprensión de la imagen, en el contexto de la manipulación digital, se dirige a un lector consciente, conocedor de parámetros semánticos necesarios para una contemplación global de la obra como resultado de un proceso implícito. El proceso de comprensión de la fotografía, tanto analógica como digital, se basa, sin embargo, en parámetros artísticos a menudo olvidados. El autor se convierte, entonces, en diseñador de ideas que se diluyen en la impresión de realidad que caracteriza a la imagen fotográfica. En efecto, es a través de su sensibilidad y sus experimentos con objetos y materiales, que se forma el enunciado genuino que va conformando el estilo propio de la imagen fotográfica. Desde allí se puede discernir una dialéctica entre el realismo propio a la técnica de registro de la realidad y la libertad de expresión del fotógrafo. Se establece, de esta manera, una especie de "metafísica" que va a dictar sus leyes dentro y fuera de las escalas de valores entre el acto creativo y el registro como testimonio del pasado.

Si la imagen creada busca relacionar las dimensiones espirituales del hombre inmerso en su entorno geopolítico, la visión del artista-fotógrafo consiste en abrir un universo de múltiples posibilidades que redefinan la noción de realidad captada instantáneamente por el objetivo de su cámara. Todos los medios, de tal forma, devienen válidos en esta búsqueda de resolver los enigmas estéticos inmersos en la noción de apariencia. Así, la impresión de realidad es instantáneamente proyectada desde toda imagen fotográfica $y$, en consecuencia, el análisis semiótico se vuelve una herramienta de descodificación de las intenciones del autor.
Aunque la fotografía parece responder a una evidencia descriptiva, su lectura representa el primer eslabón hacia su comprensión. De hecho, se considera al observador como el agente co-creador. Lo anterior, ocurre debido a que este destinatario anónimo descifra el ambiente representado por el fotógrafo y se vuelve partícipe del imaginario plasmado. Por tanto, es posible afirmar que la imagen fotográfica no está desligada de su producción cuando se la contempla, pues se interpretan tanto los recursos técnicos desde su ejecución como las temáticas que dibujan el ambiente representado. A partir de estas relaciones, dicha imagen se transforma en el trampolín comunicativo entre el autor y el lector; se establece así la condición intrínseca de la imagen-objeto como punto de partida de toda observación.

Sin embargo, la fotograf ía sigue siendo una materialización de la imagen-sujeto ya que encarna la voz del agente emisor. En consencuencia, es posible establecer la dualidad siguiente: La fotografía es una imagen-objeto cuando es apreciada por un lector y también una imagen-sujeto, puesto que encarna las intenciones del autor: es en el acto lector que se establece una relación entre el sujeto que observa y el sujeto que crea. Este papel dual de la imagen le otorga un rol de mediador comunicacional. La fotografía se transforma entonces en un puente de contacto entre la observación y la creación. Esta característica se convierte en un agente revelador de las intenciones, tanto del fotógrafo como del que contempla su imagen. 
La fotografía -como proceso entre el ojo del fotógrafo, el obturador y su resultado final- fue primero un registro técnico; no osbtante, de forma posterior, no pudo escapar desde su instantaneidad a su condición de representación. Concurre allí una relación bergsoniana entre el sujeto-objeto. La imagen deviene activa cuando se refiere al objeto en sí, pero al percibir analíticamente el mundo, el sujeto transforma lo que ve en una construcción imaginada del ambiente circundante porque lo observado se vuelve una imagen-objeto. Las representaciones -sean cuadro, dibujo o fotografía- no son imágenes subjetivas que imagina el sujeto; por el contrario, estas son imágenes convertidas en objetos por su condición técnica de ejecución, las cuales han sido encuadradas, recortadas y construidas por un emisor.

Desde los primeros retratos de Nadar o las experimentaciones sobre daguerrotipos, afloró la dimensión icónica de la fotografía. Se distinguen así dos aptitudes esenciales a su forma: la toma y la captura. En la primera, se aísla un pedazo de realidad que actúa como doble idéntico ya que este se presenta como testimonio; es objeto de la observación. En la segunda forma, desde el encuadre, se empodera la composición. Esta deviene una puesta en escena de lo observado en el entorno; es el sujeto el que habla porque al aproximarse al rostro se acentúa la mirada y, de tal manera, se fija la atención en la psicología del personaje fotografiado.

Además de sus motivaciones apreciativas, la lectura sirve para abrir ciertas interrogantes:
¿Cómo acercarse a un proceso de interpretación que posibilite la comprensión del significado inmerso en el discurso creativo, el cual está oculto en la representación? El acto lector introduce la noción de observación desde la cual se participa en el universo del imaginario del creador de la fotografía. Dicho acto es definido como una iniciación holística, ya que los sentidos de la representación habitan tanto en el acto lector como en la toma de vista. En efecto, se parte de la imagen; no obstante, esta desencadena un recorrido semántico que no tiene soporte físico, ya que pertenece al ámbito del intelecto. Se establece así un dialogo entre lo creado y lo interpretado.

La dimensión espacio-temporal no es omnipresente en la fotografía sino que deviene activa: los cuerpos, los objetos insinuados en el límite del encuadre, las sombras proyectadas, las direcciones de una mirada o de un gesto, recobran todo su sentido dinámico y lo contextualizan, tomando entonces parte activa en la significación narrativa de la imagen.

Es así como, enmarcado dentro de un proceso reflexivo, se aborda el análisis de contenido, hacia una sociología sin texto. Esta expresión posiciona la fotografía como filtro semántico en la construcción de referentes socio-culturales. Si tomamos el ejemplo del género del retrato, el estudio de la representación del cuerpo permite la delimitación de tipificaciones de orden sociológico, debido a que, desde la ontología de la técnica fotográfica, se empezó retratando la figura humana desde una observación científica. 


\section{Artículos}

Así por ejemplo, se catalogaron anomalías particulares con el propósito humanista de la elaboración de un registro médico de enfermedades. De forma simultánea, se fueron captando imágenes antropomórficas desde una inquietud etnológica; este impulso altruista fue el encargado de crear cierto interés por lo exótico, lo diferente.

Si la semiótica estudia la relación entre forma y contenido -aplicando este filtro analítico a la fotografía - se puede desvelar cierto rango ideológico, ya que se alude a un universo connotativo que le es propio al lector. Es esta franja interpretativa que libera la imagen de su yugo realista, invitando al que la contempla a ser coparticipe de la fantasía remanente que va a habitar su memoria y la percepción de su micro-historia. Existe, de tal forma, una supuesta inocencia del medio fotográfico que raramente se cuestiona cuando se retrata la historia de una sociedad. Para analizar el rol de la imagen fotográfica en la constitución de una mentalidad es necesario elaborar categorías de análisis que permitan un acercamiento a consideraciones subjetivas; dichas categorías se convierten herramientas de observación que ofrecen un punto de partida para una hermenéutica del medio fotográfico.

Siguiendo este orden de ideas, se hace necesario establecer relaciones de orden comprensivo que incentiven el diálogo entre lo epistemológico, lo histórico y lo sociológico, porque estas tradiciones intelectuales comparten un mismo núcleo de ideas que siguen siendo relevantes desde la perspectiva de las ciencias sociales. Desde esta óptica sociológica circulan ideas que permiten el acercamiento, en su espiral analítica, a un nuevo rol del lector. "El lector es el espacio mismo en que se inscriben todas las citas que constituyen una lectura; la unidad del texto no está en su origen, sino en su destino, pero este destino ya no puede seguir siendo personal" (Barthes, 1987, p.69). En esta definición del lector, Roland Barthes, desde una posición post-estructuralista, señala cómo se expande el conocimiento textual a un nivel comunicacional.

La acción interpretativa se relaciona entonces con los arquetipos de lector empírico y lector modelo descritos por Umberto Eco cuando establece las nociones de interpretación, estratificándolas de la siguiente manera: Intentio operis, intentio auctoris e intentio lectoris (Eco, 1995, p.76). Estas son las tres conjeturas del lector cuando este se enfrenta a la interpretación de un texto.

La intentio auctoris reúne el ámbito de las condiciones de creación del texto; es decir, las intenciones del autor (Eco, 1995, p.110). Estos son indicios externos a la obra que se pueden deducir a partir de la comprensión del contexto socio-cultural desde el cual se emitió. Si el término de intentio operis alude al significado intrínseco, es la semiótica la que opera como calco retórico para el análisis (Eco, 1995, p.35). La intentio lectoris reúne los parámetros de la exploración enunciativa extra e intra-diegéticos que forman parte del material del análisis de contenido, como recursos interpretativos subyacentes 
perteneciente al imaginario del fotógrafo. El compendio de todo el conjunto evocativo de la obra trabaja, entonces, desde el punto de vista de su impacto en el lector, pero también teniendo en cuenta su alcance mediático.

Usualmente la imagen fotográfica es considerada como testimonio inalterado por ser el único registro del pasado que escapa al filtro analítico. Esta representación de sociedades remotas devela cánones expresivos heredados. Aunque bien es conocido que la fotografía, como lenguaje artístico, se consolidó a la par del desarrollo de su propia técnica, sin códigos ni estética reivindicable. El rol de observador del fotógrafo lo posiciona en un pedestal, el del testigo de un acontecimiento que recobra cierto valor histórico. En la fotografía el realismo es intrínseco a su forma. Esta impresión de realidad afianza su paso a la posteridad cuando se retratan costumbres socio-culturales remotas. Esto nos lleva a mirar el panorama del contexto del tejido social de una época a través del filtro de su representación fotográfica. Es así como se conforman impresiones de realidades pasadas que van estampando en la memoria colectiva. De esta manera se puede afirmar que la lectura es el primer eslabón tanto para la apreciación como para la construcción de imágenes mentales de toda sociedad.

En el ámbito que toca a la fotografía, las tradicionales fronteras teóricas cruzan caminos entre semiología, historia, sociología, antropología y estética. Referentes que, cuando son mediatizados por la imagen fotográfica, aluden a una estructura imaginaria de relaciones asociativas cuya modalidad interpretativa revela una trayectoria socio-cultural. Estos campos del saber están invitados a dialogar cuando se emprende un análisis de la imagen fotográfica.

Analizar una imagen es captar desde la primera lectura cierto correlato entre historia cultural e historia social que permita discurrir sobre los caminos de la representación, hacia una exploración de la cultura como forma de preguntar por la sociedad. "El tipo de enfoque que hagamos de la imagen depende del campo de observación y de estudio: histórico o sociológico si nos interesa su evolución y su uso" (Joly, 1994, p.11). La premisa será observar en qué sentido el intercambio de imágenes, entre grupos e individuos, dota de sentido a su mundo mientras crea una permeabilidad ideológica.

Tanto en Europa como en Latinoamérica, los retratos realizados por los pioneros de la fotografía fijaron rostros que permanecieron para la posteridad. Los largos tiempos de pose que requería la técnica de impresión de las placas sensibilizadas a la luz, obligaron a una puesta en escena teatral, heredada de una estética pictórica. Esta forma expresiva fue evolucionando con las innovaciones de la naciente técnica fotográfica. Seguir las huellas cronológicas de los inicios de esta invención es referirse a un cúmulo de coincidencias cognitivas que surgieron a lo largo de varios siglos.

En efecto, es en el siglo XV que un pintor visionario, inventor y genio, Leonardo $\mathrm{Da}$ Vinci, se interesa por el descubrimiento que 


\section{Artículos}

Filippo Brunelleschi hizo en la primera mitad del mismo siglo sobre el principio de la formación de la imagen de una cámara oscura, aunque ya antes, Alhacen, matemático bagdalí (Ibn-al-Haytham) escribió un tratado describiendo estos principios ópticos. Más tarde, cuando la ciencia permitió trabajar el vidrio con más precisión en la época de Galileo, a principios del siglo XVII, se reemplazó el estenopo por una lupa que fue perfeccionando la nitidez de la imagen, concentrando la luz filtrada por esta lente.

No obstante, aún no se sabía conservar la imagen obtenida. Ya en el siglo XX, el soporte de vidrio cedió su sitio a la materia plástica flexible -menos frágil, más ligera-que permitió su utilización en forma de rollo para mayor almacenamiento de tomas. La sensibilidad de las emulsiones ha sido potencializada, permitiendo fotografiar sujetos en movimiento, o bajo condiciones de luces más débiles. La cámara oscura ha evolucionado de manera espectacular, hasta volverse el aparato fotográfico manual y portátil que se conoce en la actualidad, dentro del ámbito analógico, pero que usa el mismo principio de base: una cámara oscura y un objetivo (De Ferriére, 1977, pp. 9-11).

La observación del comportamiento de la luz sobre diferentes cuerpos ha permitido que todos estos descubrimientos se decanten a lo largo de los siglos. "La mayor vocación de la fotografía es explicar el hombre al hombre" (Chartier, 1996, p.16); es aquella curiosidad científica la que ha permitido que se concrete la invención de la técnica analógica de la fotografía desde finales del siglo XIX. Nombres como Niepce y Daguerre se asocian a elementos químicos como el betún de Judea o la esencia de lavanda en el cuarto del revelado. Daguerrotipia y cronofotografía se suceden, compitiendo por la conquista de la nitidez y el movimiento en los albores de este invento. Es así como una sucesión de descubrimientos ha permitido, a lo largo de los siglos, el invento de la fotografía tal como se conoce hoy, en su formato análogo.

Una nueva lógica de sentido se abre con la imagen digital. Esta gran revolución tecnológica - la digitalización de la imagen- se hace con la decodificación de un cifrado binario, primero a través de un captor CCD instalado en una cámara -exteriormente convencional- para luego ser escaneada y visibilizada en algún programa de ordenador como Photoshop (o en la misma cámara). El principio del captor CCD o CMOS permite ajustar la sensibilidad del registro de la luz mientras que se almacena en un chip cuya memoria se puede reutilizar hasta el infinito. La imagen obtenida se puede visibilizar, ser imprimida o enviada a través de las redes sociales, así como a otro destinatario.

Este cambio de la tecnología análoga a digital nos sitúa en lo que muchos teóricos llaman la galaxia Internet. Es curioso anotar cómo el procedimiento de la cámara oscura permanece inmutable desde 1430. Todo lo referente a la óptica de los objetivos se perfeccionó en los siglos posteriores, pero siguiendo el mismo principio técnico. Es así cómo la imagen numérica ha revolucionado 
el tratamiento en laboratorio que se denomina ahora cámara clara por el trabajo de iluminación y retoques que deviene una parábola infinita de manipulación de lo registrado. Queda, sin embargo, una gran incógnita de la era digital, la cual es la perennidad de archivos y colecciones fotográficas y su almacenamiento idóneo, puesto que estas imágenes se alteran fácilmente. La alianza de la informática con la técnica fotográfica está en perpetua innovación.

En la actualidad, es posible aún contemplar los frescos prehistóricos en Lascaux o Tassili o hacer reimpresiones a partir de negativos que datan de las primeras décadas del siglo XX; sin embargo, muchas fotografías digitales se pierden sin más preocupación que la de seguir disparando frenéticamente para compartirlas en el instante en las redes sociales. El valor documental de la imagen digital empadrona a los relatos, práctica que perdura hasta nuestros días, en los cuadernos y álbumes de turistas, blogueros o revistas especializadas en viajes.

Cohabitan linderos entre lectura y análisis que posiciona la representación como enclave entre el lenguaje y la cultura. En efecto, desde la perspectiva del juego de escala de la teoría sociológica, el impacto de la imagen digital reclama su rango menor porque parte del aura de veracidad de la imagen fotográfica, donde los personajes representados, los objetos o los paisajes, aparecen como vestigios arqueológicos que hablan de una cultura, desde su modo de pensar la realidad social. "El trabajo interpretativo no interviene después de la producción de los "datos" constituidos como tales por una serie de actos interpretativos" (Lahire, 2006, p. 42). En un entramado de alianzas entre el describir, retratar, o imaginar, este mecanismo de fuelle de acordeón del análisis social, se involucran asuntos temporales y espaciales en una perspectiva que fluctúa entre lo micro -que representa lo estético, formal y visual de la fuente fotográfica base de la imagen digitaly lo macro -que estaría constituido por el contenido del conjunto de significaciones, alegorías y simbolismos de valor histórico.

Constituir sentido dentro de la cultura involucra, entonces, al menos dos sistemas relacionados de representación como base de observación. "Representar significa también simbolizar, poner una semejanza delante de nuestra mente lo que le otorga sentido, mediante este «sistema de representación»" (Hall, 1997, pp. 13-15). A partir de este sistema de observación, se detecta un peculiar solapamiento entre los términos de visualización y realidad. Dentro de la perspectiva de desarrollo tecnológico de la imagen digital, la imagen fotográfica constituye una plataforma de credibilidad que posibilita la impresión de realidad como testimonio visual que va cobrando un valor histórico irrefutable. En este sentido, es el siglo XIX una época propicia a la noción de espectáculo, debido a que con las ciencias y las tecnologías nacientes, germinaba un mundo-simulacro; así, desde esta época, se asume la tecnología como elemento consustancial al progreso y al futuro. De forma paradójoca, el medio que permitió un registro veraz fue, a su vez, utilizado para contar una versión subversiva de los hechos. 


\section{Artículos}

Desde la subjetividad se aprendió a mentir a los sentidos, como si cada paso fuera una atracción de feria. En efecto, con el advenimiento de la técnica fotográfica, la pintura incursionó en senderos más alejados del realismo. La imitación del entorno pasó a ser la observación primera de la fotografía. Sin embargo, también se exploraron representaciones ficticias como lo muestran los fotomontajes de Oscar Gustave Reijlander (1898) o Peach Robinson (1899).

A continuación, se cita el ejemplo del pionero Hippolyte Bayard que muestra su simbólico suicidio. Esta experiencia se puede considerar como primera manipulación de la realidad, atisbo de un pensamiento virtual que la imagen digital va a posibilitar en los siglos posteriores. "Este pionero propuso el primer y singular fotomontaje de la historia: Autorretrato con hombre ahogado (1840) donde el fotógrafo se retrató a sí mismo, como un cadáver recuperado del río, probablemente en la morgue" (Hispano, 2001, p. 110).

[...] El cadáver del hombre que ven ustedes aquí detrás es del señor Bayard, inventor del procedimiento cuyos maravillosos resultados acaban de ver [...]. Su invento le ha proporcionado un gran honor pero no le ha dado un céntimo [...] y el infeliz se ha ahogado [...]. Pasemos a otra cosa antes de que sufra vuestro olfato, porque la cara y las manos de este hombre empiezan a pudrirse, como pueden ustedes ver. (Rabanal, 2007, párr. 2)
Se anticipa, en este ejemplo, un placer propio de nuestro tiempo que es la virtualización de la noción de realidad. Debido a este aspecto realista del sistema de representación fotográfico, se permite un formalismo que favorece una proyección virtual antes no experimentada por ningún medio de representación. La imagen del mundo se

\section{Figura 1.}

Hyppolyte Bayard, Autorretrato como ahogado y texto explicativo encontrado al dorso, 1840.

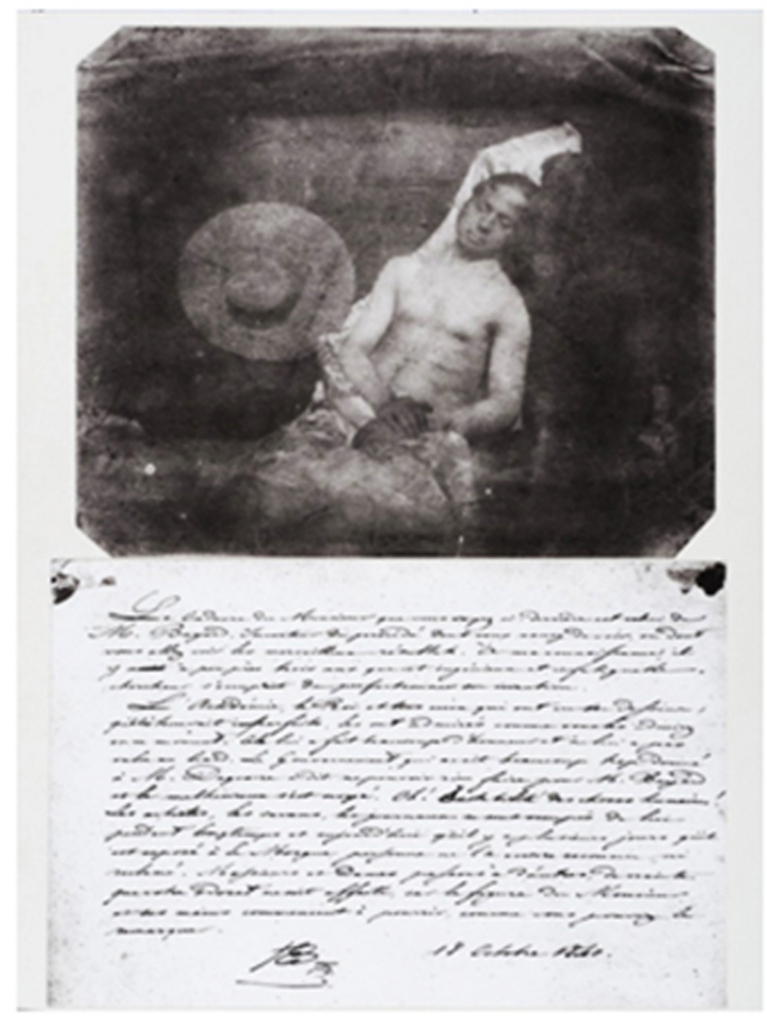

Fuente: Rabanal, L. (2007). Momentos estelares de la Historia de la Fotografía. 
corrige, se manipula o recrea según los intereses de los diferentes núcleos comunicacionales de los usuarios de cada red social. Se asiste así a un giro icónico cuyas perspectivas heurísticas parten de la imagen fotográfica, ya que se adquiere cierta libertad en la manipulación de la imagen, lo que posibilita que la imagen digital pueda convertirse en otro producto de consumo. La manipulación fotográfica se convierte, así, en una invitación a otro modo de lectura de un tejido social que puede contribuir a una contemplación proactiva.

La aparente contradicción entre la técnica de fiel reproducción de la realidad y la subjetivación de la visión del fotógrafo responde a la expresión del libre arbitrio porque se escoge el encuadre donde opera dicha visualización. Se trata, entonces, de la reivindicación del elemento de manipulación que sigue siendo decisivo en todo uso tecnológico porque "la fotografía permanecerá siempre subjetiva" (Fontcuberta, 2010, p. 234).

Entre la visualización y la espontaneidad de la toma de vista se construye la memoria colectiva, reminiscencias compartidas. A partir de allí, se fijan visiones que son dinámicas colectivas ya que crean pertenencias culturales. Estas reminiscencias se aglutinan en el cimiento del reconocimiento identitario. La visión de la historia es mediada por valores socioculturales que están sumergidos en la imagen latente y subjetiva que bordea o aureola toda fotografía, por más realista que parezca. No hay imaginación sin alguien para imaginarse; no hay visión sin alguien para ver, ni tacto sin alguien para tocar: estas representaciones son indisociables porque contribuyen a constituirse.

En relación con lo mencionado, es posible afirmar que la originalidad de una fotografía es su capacidad para existir aunque nadie la mire. Una fotografía tomada al azar se puede quedar durante años perdida debajo de un montón de papeles en un escritorio polvoriento, de tal manera que nadie se acuerde de ella, ni su autor porque también la ha olvidado. Sin embargo, esta imagen no pierde por ello su presencia, sigue existiendo. Por tanto, ¿cómo imaginarse entonces una visión que nadie viera o que desapareciera de nuestra visión? Si hay representación visual es porque existe alguien, un ser vivo que representa esta imagen; si hay representación auditiva, es que hay alguien para reproducir este sonido.

En la medida en que toda representación per se supone un ser -es decir, un sujeto de la representación- esta no puede ser compartida en un sentido estricto. Lo que alguien se representa, nadie más puede representárselo de la misma manera. Sin embargo, es ciertamente posible comunicar sus efectos sin compartir la totalidad de la visión, objeto de la representación primera. En este sentido, toda representación a través del objeto, es transmisible, intercambiable, tesis defendida por numerosas teorías del conocimiento que vuelven modelo el binomio representación-percepción desde el siglo XIX, ideas retomadas en la época moderna. 


\section{Artículos}

El concepto de representación se ha articulado alrededor de la noción de referencia, lo cual propone una repartición entre representación objetiva y subjetiva; esta reciprocidad funciona en un solo sentido: lo subjetivo remite a lo objetivo, pero lo objetivo puede no referirse a nada subjetivo. Dicha supuesta objetividad encarnaría la parte ideal, alejada de la conciencia del soporte de esta representación; por tanto, existe un juego sobre el concepto de imagen: por una parte la imagen mental, que es el contenido, representa el objeto del cual es la imagen que se puede tratar como imagen de... Por otra parte, "la imagen tiene en ella misma una especie de consistencia: constituye un cierto tipo de objeto, es perceptible sin reflexión inmediata" (Anglès, 2012, p. 121).

Es a través de este lindero donde la interpretación tiene en cuenta los diferentes grados de análisis; es decir, los aspectos hermenéuticos, semióticos e iconográficos. De esta manera, se pone a discurrir la historia del estilo con la interpretación simbólica. En este punto, la síntesis de parte de la teoría sociológica contemporánea que hace George Ritzer aclara la importancia de los planteamientos metodológicos de Pierre Bourdieu: "Él fue uno de los primeros a posicionarse desde una perspectiva estructuralista/constructivista" (Ritzer, 2002, p. 501). Las investigaciones de Bourdieu analizan los efectos del medio fotográfico en la sociedad; asimismo, dicho autor identificó la importancia social de la conexión entre este dispositivo de registro de la realidad y la identidad cultural. Es a partir del conjunto de la obra del iconólogo Erwin Panofsky ${ }^{2}$ que Bourdieu sintetizó la dialéctica entre dos conceptos: el habitus y la noción de campo. La brecha de las estructuras objetivas y de los fenómenos subjetivos fue revalorizada a partir de estos aportes; se abrieron, de esta manera, las perspectivas micro analíticas de las ciencias sociales:

Por un lado, las estructuras objetivas [...] forman la base para [...] las representaciones y constituyen las constricciones estructurales que influyen en las interacciones: pero, por otro lado, estas representaciones deben también tenerse en cuenta particularmente si deseamos explicar las luchas cotidianas, individuales y colectivas, que transforman o preservan estas estructuras. (Bourdieu, 1989, p. 15)

Precisamente estos son los síntomas culturales que entran a jugar un papel determinante en el discurso sobre las ideas y las tradiciones. Aparece en escena el imaginario fotográfico asentado en una descripción fáctica de los motivos artísticos, una mirada teórica que tiene en cuenta la familiaridad de los objetos y las acciones representadas como una invitación al sendero discursivo hermenéutico. En este mismo orden de ideas, las aportaciones de Burke contribuyen a la teorización sociológica que tiene en

${ }^{2}$ Cuando su obra se tradujo al francés. Arquitectura Gótica y Renacimiento Escolástico (1967). 
cuenta la historia del estilo en la expresión artística (Burke, 200, p. 174).

A partir de estos aportes a la reflexión sociológica, se puede señalar que en la era tecnológica, la representación reagrupa en gran parte una dimensión psicológica, desde su sistema perceptivo contenido en la teorización de una conciencia colectiva mediatizada por la imagen digital. La virtualización mediática consiste en una realidad cuya escala "implosiona" a partir de la fotografía al entrar a la era digital. En la era contemporánea la creencia en el objeto mediático transforma la percepción del entorno y la inserción del sujeto en su perspectiva misma. Así, lectura y análisis forman los dos ejes de la apreciación de la imagen digital, la cual va configurando una sociología sin texto porque esta representación fotográfica mediatiza nuestras relaciones socio-culturales.

Introducir, entonces, la noción de isotopía en el marco de la lectura de la fotografía permite abordar el análisis de contenido de un texto visual desde su globalidad connotativa. "La repetición de algunos elementos semánticos o gramaticales son las isotopías, ellas establecen el sentido en el texto" (Greimas, 1979. p. 13). ${ }^{3}$ Este término es aplicado en el contexto de la teoría semiótica y, en efecto, si se profundiza esta noción de isotopía se logra percibir que: "La isotopía es la condición estructural indispensable para el funcionamiento del mensaje lingüístico para que pueda ser comprendido como un todo significante" (López y De Vicente, 1985, p. 463).

Aquí, el concepto "lingüístico" se entiende en el marco de la teoría de sentido que debe ser generadora y concebida "bajo la forma de desvelo progresivo del contenido" (Greimas 1966). "Esta es una manera de proponer lecturas isotópicas como alternativas lúdicas para tomar el pulso biométrico a la vigencia del legado fotográfico - este como base de la imagen digital- para abrir horizontes a las posibilidades interpretativas. Se genera, de tal forma, una búsqueda de linderos interdisciplinares que parte del postulado siguiente: la manipulación digital se conecta en un nivel holístico con el terreno de la teoría de las ciencias sociales, porque opera una revalorización de las perspectivas micro-analíticas, ya que - partiendo del medio fotográfico- es la dimensión humana la que está en juego, tanto de forma temática como técnica.

La muerte de la fotografía después de un siglo y medio dejando constancia y conmemorando la muerte, la fotografía encontró la suya propia en algún momento de la década de los 80 , a manos de las imágenes creadas por ordenador. La capacidad de alterar una fotografía digitalmente ha anulado la condición básica

\footnotetext{
3 "La repetición de algunos elementos semánticos o gramaticales son las isotopías, ellas establecen el sentido en el texto". Traducción del francés.

4 "Bajo la forma de desvelo progresivo del contenido". Traducción del francés.
} 


\section{Artículos}

de la fotografía: cuando se ha abierto el obturador algo debe haber estado ante el objetivo, aunque las preguntas sobre la autenticidad de lo fotografiado permanezcan en el aire. Ahora es posible crear "fotografía" de escenas que jamás han existido sin que la falsificación pueda apreciarse de forma directa. (Mirzoeff, 2003, p. 130)

En estricto sentido, esta muerte es la desaparición del rol del testigo ocular que tradicionalmente se le asignó a la imagen análoga desde su descubrimiento. Con la digitalización, la representación se reclama del universo ficcional porque esta tecnología permite manipular la realidad añadiendo elementos, alterando y retirando trozos, para crear un mundo ficticio que tiene un aspecto aún más creíble que "lo real" pero que es fabricado desde la edición. Así, con la fotografía, se entra en la era de lo virtual cuyo lenguaje se torna isotópico. Lo anterior ocurre porque -teniendo como base el medio fotográfico- en la era virtual se altera la posición tradicional del observador pasivo. De forma contraria, el usuario es involucrado desde la captura con el objetivo de su cámara, el cual, luego en las descargas a su ordenador, analiza sus imágenes y las manipula digitalmente para compartirlas, de forma posterior, en las redes sociales.

Es así como sujeto y objeto se influencian mutuamente. En este punto, deben tenerse en cuenta las discusiones contemporáneas en las ciencias sociales y humanas. Para el efecto, el modelo de Giddens abre una doble hermenéutica desde su teoría de la estructuración sociológica a partir del estructuralismo de Althusser y del subjetivismo de Weber (Giddens, 2012): estos conceptos de capacidad y cognoscibilidad sugieren una "agencia" que introduce a la acción social. Si esta noción es transferida al conocimiento de las prácticas fotográficas, su herencia, su significado, se puede entender como práctica social.

Si bien es cierto que, por tradición cultural, la fotografía adquirió un valor de prueba de veracidad sin cuestionamiento, la veracidad del medio es percibida como realidad inalterable. Este concepto de capacidad es entonces interpretado como los diferentes modos de hacer imágenes a partir de una fotografía, lo cual considera la aparente inmediatez de la recepción y lectura de la imagen virtual como fomento para su divulgación. La noción de agencia deviene, finalmente, en un factor activo que re-significa.Tal modo de concebir la acción deriva del hecho de considerar la visión como un fenómeno selectivo y es allí donde sucede la isotopía en la imagen digital.

En el marco de la genética, la vista se puede corregir ajustando la nitidez con lentes y dioptrías para la miopía o la presbicia; de igual manera, el enfoque fotográfico es también filtrado por la óptica con el juego de los objetivos: por ejemplo, un gran angular abarca mucho más que la mirada, o a la inversa, el macro de un teleobjetivo devela universos imperceptibles al ojo. Es así como el espacio fotográfico puede hacer aparecer 
una vista nítida en su totalidad, mientras que el ojo humano se limita al objeto en el que esté centrando su atención en determinado momento; lo demás aparece borroso y es solo el cerebro y las referencias quienes completan la totalidad de lo que estemos mirando. De tal forma, "El espacio es tanto un hecho existencial estático (dado que no podemos existir fuera del espacio) como un fenómeno determinado dinámica y socialmente" (Boyarín, 1992, p. 3). Con lo anterior, se subraya el hecho que el espacio es también el resultado de un acto cognitivo inconsciente, como sucede con las ensoñaciones y los procesos de remembranzas.

La creación digital presenta un nivel de "agencia”, cuando se establece el propósito prospectivo siguiente: “¿Pueden y deben la práctica de la fotografía y la significación de la imagen fotográfica proporcionar material para la sociología?" (Bourdieu, 1963, p. 15).

Desde la óptica de las artes visuales, el terreno fértil que ofrece la web distribuye indicios y designa pautas abiertas por la transferencia del sentido plástico y tecnológico. La ciber-cultura invita a discurrir sobre la influencia de las tecnologías digitales en el ámbito de la investigación sociológica; de ahí la importancia de crear semilleros de investigación, cuya misión gire alrededor del desarrollo de nuevas formas de utilización de la tecnología digital y así poder suscitar un trabajo de reflexión sobre el impacto del uso creativo de la fotografía, puesto que hace ya más de dos décadas, se vive en una era digital donde la fotografía es el pilar visual.
La plataforma digital se está convirtiendo rápidamente en el alfabetismo del presente, ya que se diseñan sitios $w e b$ como proyectos educativos, se integran vídeos, gráficas y animaciones. Esto requiere adoptar una actitud lúdica y permisible frente a cierta visión museística del saber. En efecto, toda obra reconocida como patrimonio cultural se abre al público en general. Así, se propone abrir una discusión con la obra, tomando la libertad de intervenirla y así repensarla con el objetivo de pontencializar, de esta forma, un análisis visual para actualizar el abanico hermenéutico.

Como un lienzo en blanco que anhela el gesto arqueológico del excavador para elucidar su devenir, la imagen digital trabaja el signo visual desde la imitación posicionándose como calco de citación del original. Se experimenta así en la creación de una peculiar trenza semiótica que establece un diálogo intertextual, y en consecuencia, se abre una invitación, tanto en la lectura pictográfica como en la de los códigos evocativos, que interroga el halo de veracidad del medio fotográfico.

A continuación, se citan ejemplos de aplicación isotópica en la imagen digital a partir de obras de Melitón Rodríguez pertenecientes al patrimonio fotográfico del archivo de la Biblioteca Pública Piloto de Medellín, de donde fueron adquiridos los derechos para el trabajo con el semillero de investigación de la Escuela de Artes de la Universidad Nacional de Colombia, sede de Medellín. 


\section{Artículos}

Figura 2.

Melitón Rodríguez. Germán Jaramillo (1882).

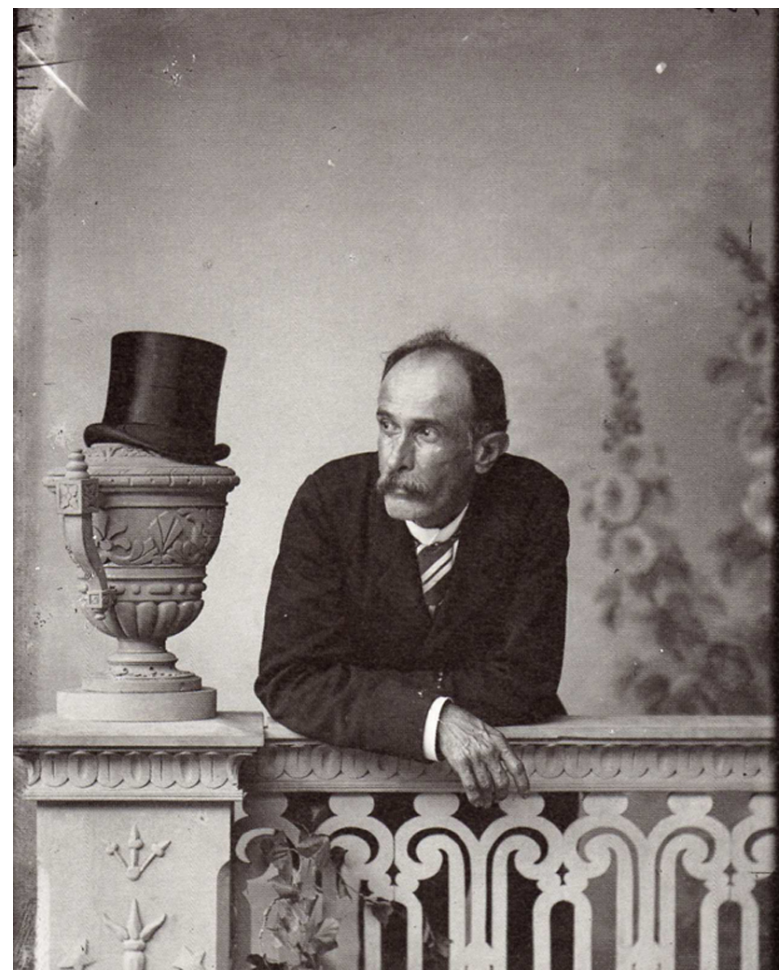

Fuente: Archivo BPP.

En el primer ejemplo que se cita, se muestra un experimento de isotopía con connotaciones cinematográficas donde el escenario recreado se refiere al universo del celuloide. El rango inspiracional se aleja del universo fotográfico original permitiendo adentrarse en las connotaciones de las primeras imágenes en movimiento.

La utilización del icono de la luna sacada de la película que data de 1902, Voyage á la Lune del pionero Georges Méliès, permite

\section{Figura 2a.}

Juan Camilo Hernández.Germán Jaramillo (1882). A la manera de Meliés, (2012).

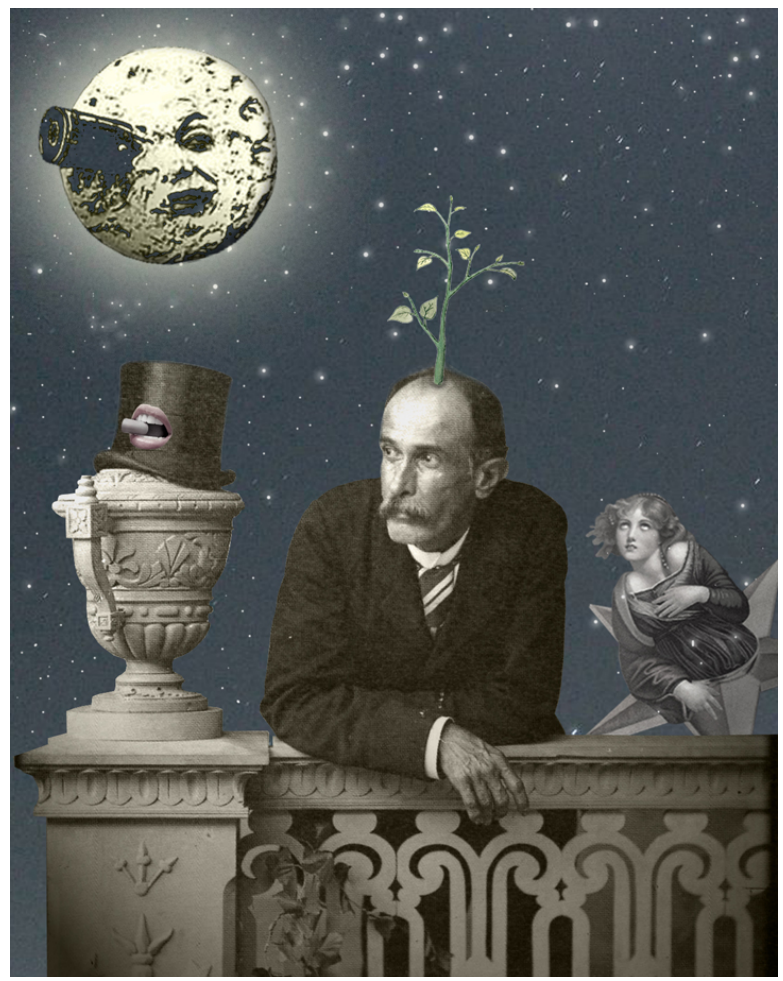

Fuente: Semillero

el traslado, a su vez, en una espiral de significantes a la obra de Jules Verne que le inspiró: De la Terre á la Lune. Lo que Méliès inventó es una manera de poner la representación cinematográfica al servicio de la ilusión. Esta luna deviene un ícono de la magia del montaje por desaparición y sustitución de elementos. Es lo extradiegético que se ha posicionado en el lugar del punctum, zona de atracción semántica según Barthes (1982, p. 64). El personaje pasa a ser el contexto y no el protagonista. La 
Artículos

Figura 3.

Melitón Rodríguez. El ángel de la esperanza (1908).

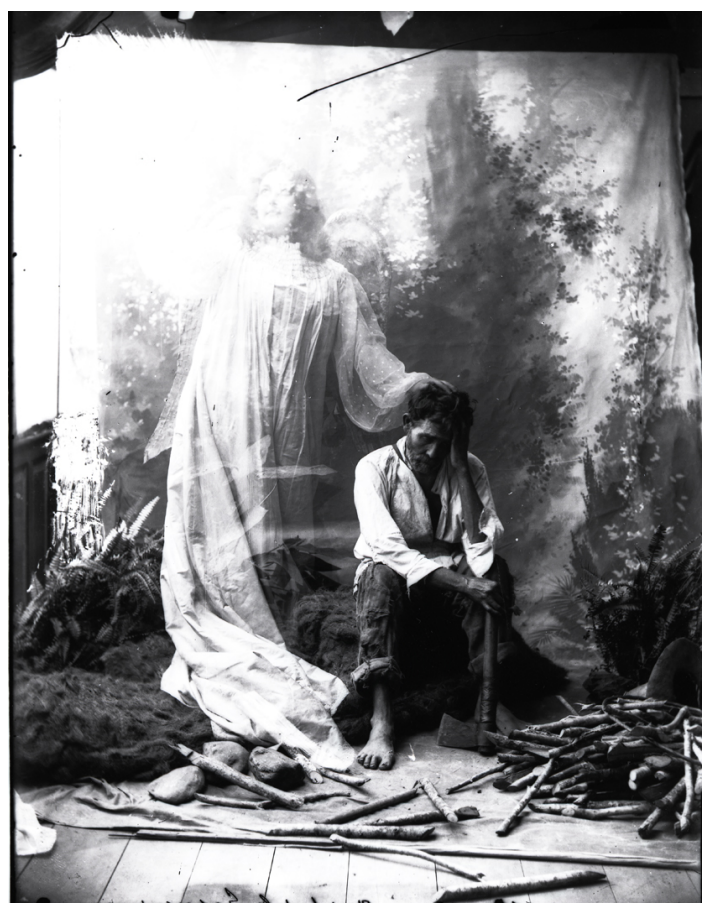

Fuente: Archivo BPP.

\section{Figura 3a.}

Juan David González. Los tres en la habitación de Van Gogh (2012).

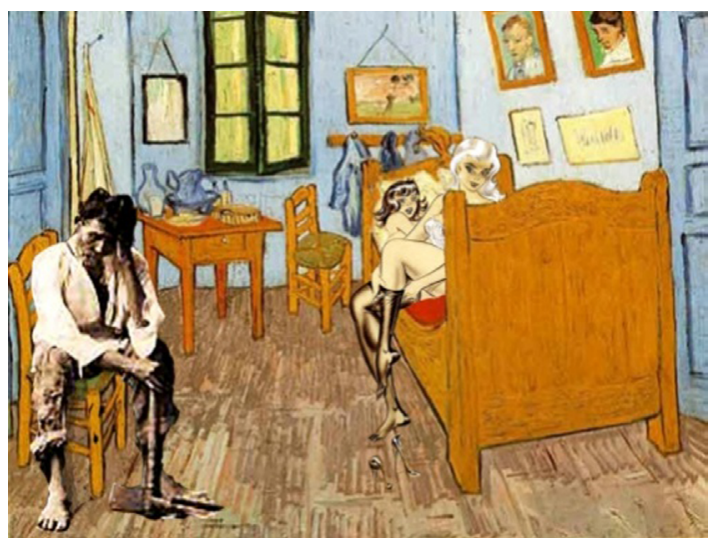

Fuente: Semillero ensoñación que se le atribuye deviene entonces en elementos cinematográficos.

El tono azulado añadido habla también de frialdad, de un relato fuera del contexto real, el del celuloide. Este es el rango enunciativo del studium, zona de las connotaciones socio-culturales extra-diegéticas (Barthes, 1982, p. 65). El sombrero de copa tiene dibujado una boca que fuma un cigarro, lo cual remite al mundo aristocrático del siglo XIX con el dejo humoristico propio a la caricatura. Este mismo tono se refuerza cuando brota de la cabeza del personaje una rama. Tambien, una figura de ángel asoma mirando al vacío. Lo anterior, se definen como apliques ilustrativos que afirman el tono burlesco de esta imagen, enviándola a un registro alegórico que pertenece al relato cinematográfico, con lo cual se refuerza la intentio lectoris.

El universo evocativo de esta propuesta visual habla de un subtexto que toma como referente la estetica post-modernista en donde se connota un mundo de la ciencia ficción. Es curioso anotar que en la mayoría de los resultados del semillero citado, se perfiere escoger imágenes de exploración más alejadas del tejido enunciativo original, y tener la libertad de proponer narrativas ilustrativas propias.

El ejemplo siguiente ilustra el abanico de inspiración que ofrece el arte contemporáneo.

El rango interpretativo de la isotopía anterior se alimenta de connotaciones plásticas que hacen referencias al pop art. Poner como 


\section{Artículos}

Figura 4.

Melitón Rodríguez. Veneno (1895).

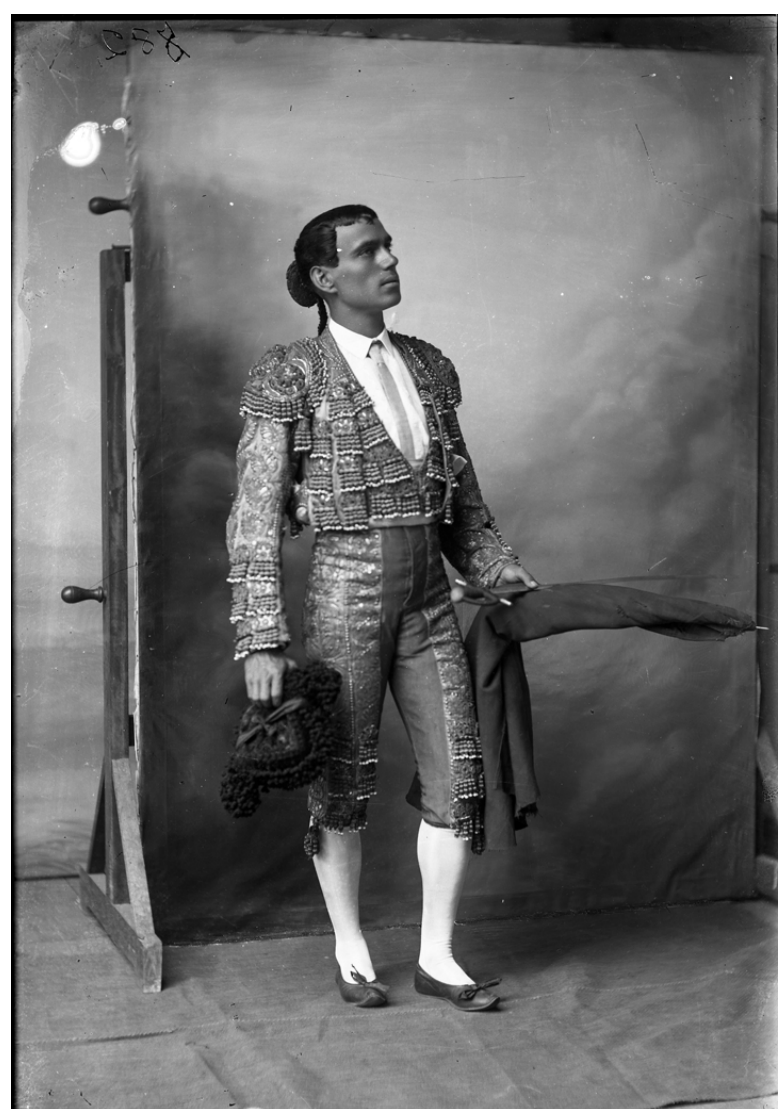

Fuente: Archivo BPP

telón de fondo las polaroides del icónico de la serigrafía de los años setenta, Andy Warhol, hace bascular la descisión intepretativa, ya que es la repetición de la cabeza de toro y este tono rosado fluorescente que caracteriza la paleta de color del artista, lo que le arrebata el protagonismo al torero retratado en la fotografía original.

En los tres ejemplos anteriores, el semillero examinó la apropiación del universo
Figura $4^{a}$

Juan David González. Veneno Warhol (2012).

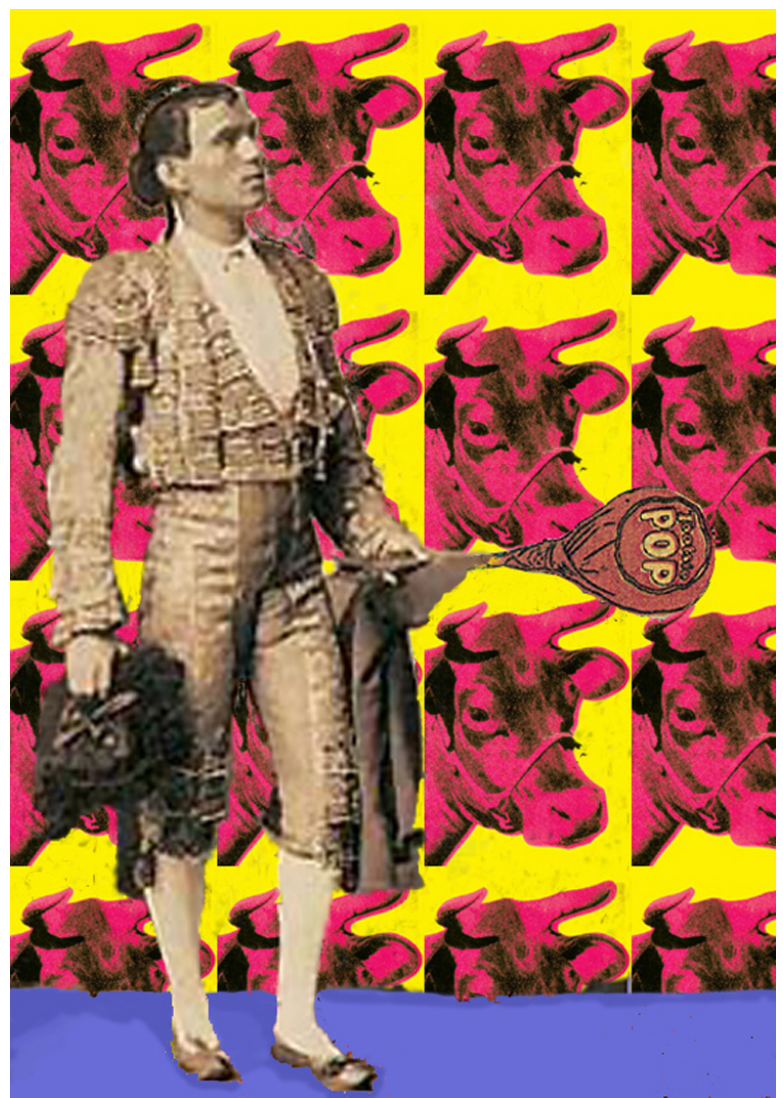

Fuente: Semillero.

fotográfico de Melitón Rodríguez trabajando isotopías en la imagen digital. Con el fin de motivar la lectura y la interpretación de los argumentos narrativos inmersos en la composición fotográfica se propuso jugar con la yuxtaposición. En efecto, se extraen más ideas cuando se comparan dos universos visuales. La dualidad de las imágenes yuxtapuestas hace aflorar casi automáticamente diferencias y similitudes que son creadoras 
de nuevos sentidos, llamado en el lenguaje cinematográfico, el "efecto Kuleshov" (Konigsberg, 2004, p. 186).

Existe un intersticio holístico donde las connotaciones afloran en el imaginario del que contempla la imagen cinematográfica, pero también ocurre con el lector invitado a contemplar un montaje fotográfico dual. Este sentido es parte integrante de la sintaxis fílmica, en donde el espectador se convierte en partícipe del argumento, creando significados semánticos en un proceso simultáneo de lectura fílmica. Así, el lector construye emociones en una proyección psicológica inconsciente que le permiten identificarse con los personajes representados en los encuadres, viviendo virtualmente sentimientos alentados por el desfile temporal de la comparación de expresiones y experiencias narrativas proyectadas en la representación de isotopías en la imagen visual. Aunque los códigos de lectura son siempre culturales, se aprecian de forma automática, ya que responden a un efecto perceptual producido con la misma sucesión de imágenes y se genera un sentido de espacio para el espectador que permite una proyección onírica cuya percepción realista favorece una experiencia vivencial. Es entonces esta ubicación colindante de dos fotografías la que permite una lectura comparativa; el calco inmanente crea una clasificación lúdica basada en el lenguaje de las formas visibles para desvelar el poder de la máscara en su lectura, como arquetipo de una sociedad.

Es en este lindero holístico donde anida la interpretación que permite entablar una reflexión intelectual, emocional y estética sobre la capacidad de la fotografía, para involucrar al espectador con diversas perspectivas sobre el mundo, basadas en la impresión de realidad perteneciente al universo fotográfico trabajado. De esta manera, se llega a involucrar la psiquis hasta suplantar el contexto socio-cultural presente en la fotografía de archivo; de ahí que sea posible argumentar que pensar fotográficamente cobra un nuevo sentido aplicando isotopías en la imagen digital.

\section{Referencias}

Anglès, M. (2012). Filosofía postmetafísica. Veinte años de filosofía francesa contemporánea. Capítulo: "De la fenomenología a un realismo contextualista". Barcelona: Llevadot y Riba Editores.

Barthes, R. (1982). La cámara lúcida, Nota sobre la fotografía. Barcelona: Gustavo Gili. S.A. El susurro del lenguaje. Capítulo: "Más allá de la palabra y la escritura". Barcelona: Paidós.

Bourdieu, P. (1963). Essais sur les usages sociaux de la photographie. Social space and symbolique power. Paris: Éditions de Minuit.

Boyarín, J. (1992). Storm from Paradise: the politics of Jewish memory. New York: Routledge.

Burke, P. (2000). Historia y teoría social. México: Editorial del Instituto Mora. Visto y no visto. El uso de la imagen como 


\section{Artículos}

documento histórico. Barcelona: Editorial Crítica.

Chartier, R. (1996). El mundo como representación. Historia cultural entre práctica y representación. Capítulo 2. Barcelona: Editorial Gedisa.

De Ferrières, M. (1977). Eléments de technologies pour comprendre la photographie. Chap. 1: "Historique: de l'argentique au numérique”. París: Édition Eyrolles.

Eco, U; Rorty, R. ;Culler, J. y Brooke-Rose, C. (1995). Interpretación sobre interpretación. Cambridge: University Press.

Giddens, A. (2012). La teoría de la estructuración - Sociología - Educatina. Recuperado de https://www.youtube. com/watch? v=a0i57Rmyrvg

Greimas, A. J. y Courtès, J. (1966,). Sémantique structurale. Sémiotique. Dictionnaire raisonné de la théorie du langage. Chapitre: "Sémantique". Paris: Larousse.

Hall, S. (1997). Representation: Cultural Representations and Signifying Practices. Londres: Sage Publications.

Hispano, A. (2001). Imágenes para las sospecha, Falsos documentos y otras piruetas de la no-ficción. Capítulo: "Lo falso, lo parecido y lo hiperreal, breve aventura virtual del siglo XIX", Apartado: Maravillas del otro mundo. Sitges: Ediciones Glénat, colección para papel $n^{\circ} 5$.

Joly, M. (1994). Limage et les signes Approche sémiologique de l'image fixe. París: Nathan.

Konigsberg , I. (2004). Diccionario técnico Akal de cine. Tres Cantos: Akal.

Lahire, B. (2006). El espíritu sociológico. Capítulo 2: "Arriesgar la interpretación. Los derechos y deberes del intérprete". Buenos Aires: Manantial.

López Covadonga, A. y de Vicente, E. (1985). Isotopía y análisis textual. Actas del Congreso Internacional sobre Semiótica. Recuperado de: https:// books.google.com.co /books?id=pHcsgiEWdgAC\&pg=PA467\&lpg=PA467\&d$\mathrm{q}=\mathrm{LECTURAS}+\mathrm{ISO}$ T \% C 3\%93P I CAS\&source =bl\&ots $=$ VD8Q2g1I $6 Z \&$ sig $=$ NVF7yZNvSPLS2rF0Ly6agGeiWnY\&hl=es-419\&sa $=X \& e i=i 8 \_x V-$ J6RKrHsQTNw4DADQ\&redir_esc $=y \#-$ $\mathrm{v}=$ onepage $\& \mathrm{q}=\quad$ LECTURAS\%20ISOT \%C3\%93PICAS\&f $=$ false

Mirzoeff, N. (2003). Una introducción a la cultura visual. Barcelona: Paidós.

Rabanal, L. (2007). Bayard se ha ahogado. "Momentos estelares de la historia de la fotografía". Pestaña: Orígenes/una anécdota. Recuperado de http://www.luisrabanal.es/mef/origenes/unaanecdota/ index.html

Ritzer, G. (2002). Teoría sociológica contemporánea. Capítulo 10: "Principales ejemplos de integración acción-estructura”. México: Editorial McGraw-Hill. 